\title{
Snapchat: a brief encounter
}

For users of the mobile image-messaging app Snapchat, expressiveness is largely mediated through in-built filters, described as lenses, and the extensive use of short pieces of text and emojis. It is also contingent upon the disappearance of the image after a set interval of time. The certainty these images will not be retained - that they will disappear from the recipient's mobile device - sanctions a degree of liberty in what is sent between users. However, there is also a reciprocal level of trust, since despite the app itself having no feature to save an image, recipients are able to screen capture any images they receive. Should the recipient screen shot an image, the sender receives a notification that their image has been saved in a screen capture. Inevitably, this is likely to elicit a spontaneous reaction of despair, anguish and distress that there has been a breach of the code of disappearing images, implicit in Snapchat's communication method.

What then is the purpose of an imaging application, which takes portraits that deliberately do not conform to the normative conventions of the human face? Snapchat lenses are based around facial recognition software, enabled when using its augmented reality features. In essence they offer users the opportunity to do something different with the 'selfie.' But why do Snapchat users want to overlay rabbit ears, or distort their own features, or draw on graphic hats and glasses or even swap their face? Humour, the self-deprecating kind, plays an important part in this process. And there can be little doubt self-deprecating humour is more permissible because the images are not permanent; they have a time-limited existence. However, what does Snapchat do to the reference points of photographic portraiture? Furthermore, what does it challenge in terms of our understanding of image, when it is based on a premise of disappearance rather than preservation? 
In this essay, I propose Snapchat portraits express not the face as image but image as perplexing, disappearing, mutating phenomena. Through its vague relationship to the genre of photographic portraiture, Snapchat is not so much concerned with identity, likeness or reproducibility. Instead, it stresses duplication, disguise and disappearance as the dominant features of the self in contemporary culture. Furthermore, with their use of lenses, filters and distortions Snapchat messages unsettle our notions of the index - wherein what is shown in a photograph was also once in front of a camera - and with their built in disappearance they challenge any sense of image as a memory prosthetic. In a culture of obsessive and compulsive picture making, Snapchat as a way of making portraits, is not overly concerned with creating image likenesses nor is it aligned to any recognisable notions of identity. Instead, it contributes to the mass production and proliferation of images that we are engrossed with and experience today. I argue it is this activity of making images that defines who we are, more than any visual representation of our faces. Taking photographs, especially of ourselves, is what we now do.

The photographic snapshot has always been an image of a captured moment, seemingly forever frozen in time. It has regularly shown us the toothless grin, the funny face, the smile and even the tears of experiences. Historically, snapshots have always been about the everyday, the banal, the repetitive, the clichéd events that are part of everyone's lives. And by using Snapchat, almost any everyday activity can be combined with the production and distribution of an everyday image. Rubinstein and Sluis suggest snapshots make "specific historical conditions appear natural and universal" (2008: 24). But does this universal activity of making and sending selfportraits, pulling stupid faces, grimacing, pouting and contorting how we look in order to make others laugh, reveal some truth about the sadness that lies behind the face of the clown? Perhaps, the very reason we need this kind of distraction - of making images of ourselves in order to make others laugh - is because of the unbearable certainty that there is so little keeping us from the day to day despair of 
being incorporated into a network of human and non-human forces. Despair felt because, as with the snapshot, the underlying condition of human life is that of an "insecure presence" (Ibid: 23). Snapshots may be easily disregarded, not only due to their everyday subject matter but also because they are absorbed into or lost within a continuous flow of data.

It is the timed deletion of Snapchat images which creates an emptiness and a demand that inevitably needs to be filled with more images. In this way images become inconclusive accounts of unreal, comedic gestures and fake cartoon like faces, all of which somehow need to be continuously reproduced, as if doing it again will at some point, resolve why it was done before. Perhaps, it is the specific 'cartoon like' qualities of Snapchat images that create the repeating urges, since in the world rendered in most cartoons there is no guilt only fun, no one dies and any discernable ending can seemingly be redrawn.

As an image messaging application and the two words 'image' and 'message' are used in their broadest sense. Snapchat is unquestionably a form of communication, a way of sending messages. But what it creates are neither messages as we usually read them or images as we used to understand them. What then is the purpose of an imaging app, which encourages taking portraits - selfies - that deliberately do not conform to the normative conventions of the human face? I suggest, it is because images no longer matter. Maybe, because we have seen and produced so many images, there is now nothing unique or special to be shared. Or perhaps we are so obsessed with making 'selfies' because the self is in crisis, desperate to be recognised, differentiated and understood.

Of course photography has always been able to record, witness and show us things good things and bad things - but we should not forget photography also shapes our responses, interactions and it creates affective intensities. This being especially so 
since photography is more embedded into the character of the Internet and its information networks, its mobility and its content creation. In recognising how "technologies co-evolve with the dynamics of systems of which they are part" (Hand 2010: 15) photography is clearly now not what photography visibly once was. Photography, in a pluralistic sense - in its many forms - is not a separate apparatus passively recording reality; it is causal in the disruption of what is happening and an agent within the disruption it creates. Through photography we assume a bearing on how we experience reality, not because we actually make images, but because we make images possible. Photography is not a Kodak moment, nor is it a click of the camera shutter. It is the conditions that make those things imaginable. Photography, whether it comes about through Snapchat or any other means is the rendering of a rupture in the systematic ordering of reality that then makes something like an image occur.

In its digital form photography now stresses properties aligned more closely to repetition, to the flows of data, to incorporation, to being a form that can re-form, to the virtual and to the invisible. In the same way, Snapchat selfies express not the face as an image but image itself as confusing and changing object. Demonstrating a shift in image making that is now mediated and dominated by software, by the algorithm, rather than by cultural practices, these images of humour, with their contorted facial expressions and augmented reality overlays, are inevitably all stored virtually as data in databases somewhere. They await algorithmic transformation from numbers into visible pixels. Thus the digital image becomes the interface between human and non-human communication.

Through its augmented overlays, the virtual world of screens and the physical world of objects are no longer mutually exclusive. Snapchat brings interpenetration between the two. But a further question is whether Snapchat provides something new when what it presents are not simply seen as unconventional, augmented selfies 
for bored people to amuse and communicate with. Instead, I suggest it is the restaging of desire. It provides comedic misrecognition: an overdetermination that fuels a perception of a fantasy suggesting we all want to be funny, to entertain and to be liked but in order to do this we have to be someone other than who we are.

In communicating without saying very much, Snapchat is paradoxical. Likewise it presents a challenge to creativity and against the very notion that we can reveal something about our reality by depicting it. As an application Snapchat largely governs creativity; it limits the extent to which the images it can produce express anything substantially different. This constant production and exchange of images rarely tells us anything visually new about the world, instead, these images simply reproduce the economic conditions of capitalism. Snapchat updates its lenses, making new ones available or even providing location specific overlays. These updates serve only to encourage continuous changing and replacement of the who we weren't yesterday with the who we are not today. Portraits made with Snapchat are facets of an inexact and shifting performance of an identity in crisis. One that is fused with status statements, comments or proclamations that attempt to validate, vindicate or vitalise a disappearing presence. What these portraits really do is signal disappearance in every sense: disappearance of the image and of the human subject. With their ephemeral nature and their obscuring of visual similarity and their casual relationship to meaning, Snapchat portraits are an exemplary vanishing act.

When disappearance becomes the sin qua non of image, then image is no longer the site of history, memory nor meaning in any permanent sense. Somewhere in the database our likenesses linger, like corpses awaiting identification. For Freud, the face is how we identify with and have empathy for our neighbour. It is the face which covers over and masks the horror inside us. But as Slavoj Žižek suggests, what if the covered face - the distorted, augmented, Snapchat joke face - creates anxiety because it "confronts us directly with the abyss . . . the neighbour in its 
uncanny dimension" (2011: 02)? In this way the overlays eradicate the protective cover of the face and show us the strange 'other' staring back directly at us. Leaving us, briefly, for a limited time, confronted by a de-subjectivized subject.

Because the duration of these images is precisely controlled, they create a present moment in which the sender and receiver do both fleetingly exist together. This time is restricted and short lived with Snapchat controlling the tempo and form of perception. This is instant time - a time of the Internet, a time of computers, phones and devices. Distorted and filtered Snapchat portraits are not images of humans they are images of fictional non-human renders based on real faces. What they depict, albeit briefly, is time as a limited and controlled commodity. What they give to us is not an easily recognised subject, but a subject who understands there is no longer and perhaps never was a subject to be known.

\section{References:}

Hand, M., 2010, 'The Rise and Fall of Cyberspace, or How Cyberspace Turned Inside Out', in Hall, J. Grindstaff, L. Ming-Cheng, L. (eds) Culture: A Sociological Handbook. London: Routledge.

Rubinstein, D., \& Sluis, K., 2008, “A Life More Photographic” in Photographies, 1:1, 9-28 Žižek, S., 2011, Living in the End of Times, London: Verso. 
